\title{
$\mathfrak{I} \mathfrak{n} \mathfrak{h} \mathfrak{a} \mathfrak{l} \mathbf{t}$.
}

\section{Erfter Elyeil.}

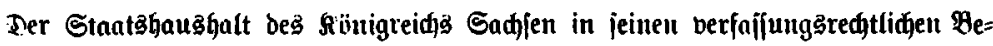
ziebuntgent

$$
\text { Erfter } \mathfrak{A} \text { biduitt. }
$$

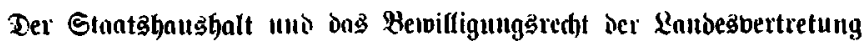

3rociter Mbidnitt.

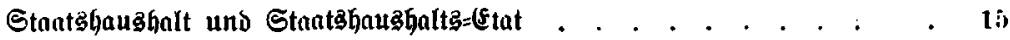

I. Entftehung Des Stratshaughalta=-Etats . . . . . . . . 15

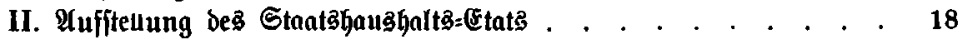

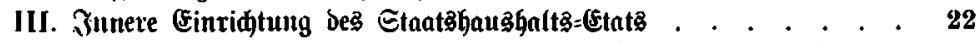

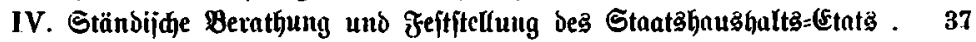

V. Rionigliđe Sanftionirung und Berabfăbiedung bes Stantahaushaltà= Etat3...................444 44

VI. Staatabausholts-(Etat uno Finauzgeję̧ . . . . . . . . . . 45

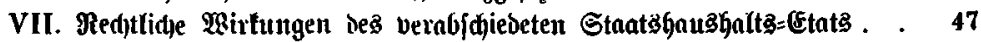

Dritter $\mathfrak{a} b[\mathfrak{d} n$ itt.

Stratâvermögen .

Bierter $\mathscr{U}$ bidnitt.

Stantsjduliden

if ünfter $\mathfrak{A} b$ 中nitt.

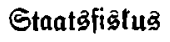

Sedster 9 bjanitt.

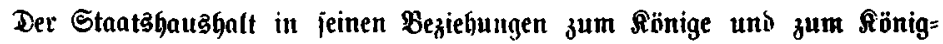
lidien .

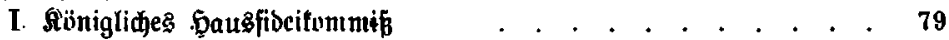

IJ. Ä̈niglide Bibillifte . . . . . . . . . . . . . . . . . . . . . . . . . . 82

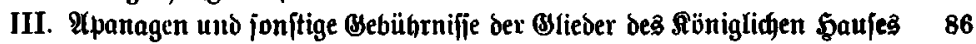

Siebenter $\mathfrak{A} b$ dinitt.

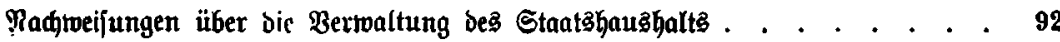




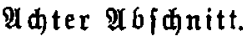

Stantride Fontrole dę @tuatshaushalt?. . . . . .

Meunter abjuitt.

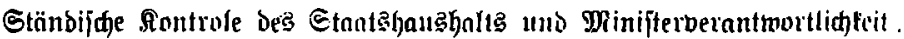

108

\section{3uriter El|pil.}

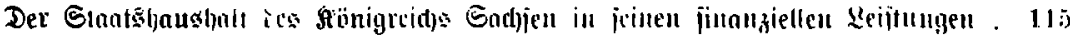

(Eriter ?(bjd)uitt.

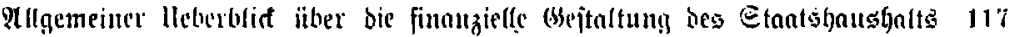

Bucilcr 2 bidult.

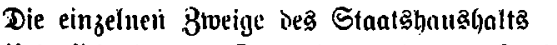

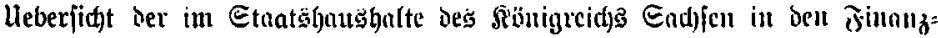
perioben bou 1834 bis mit 188 is aufgetoumenen Ucherjejiffie unb nutf= getwendeten $3 u j$ hiifje . . . . . . . . . . . . . . . . . 24:

Entwiffelung Des ftantficl)'n Berntögens uno ber ftantlichen Srlyuloen in ben Fiınnzperioden bon 1834 bie utit 1885. . . . . . . . . . . 257

Snduegifter . . . . . . . . . . . . . . . . . . . . 25!

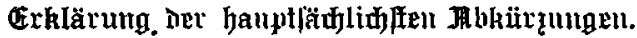

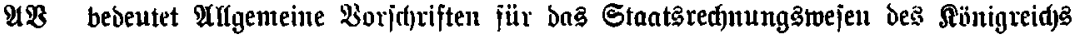
Sadjien.

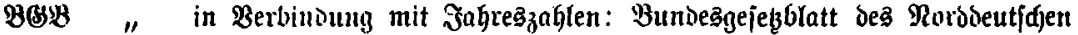
Buntes, in Berbintung mit Raragraphenzahlen: Bürgerlides (Sejeb= bưf für bus Rünigreid) Sndjien.

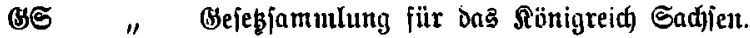

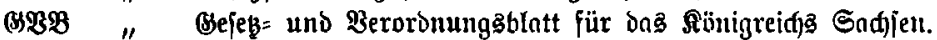

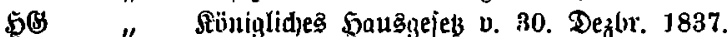

$\Re(38$ " Meid)

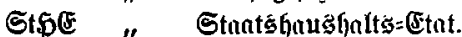

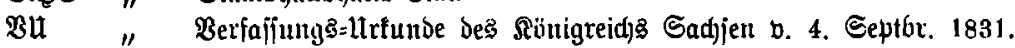

